\title{
pommalina
}

(8)

\section{Diarreia aguda e crónica}

Autor(es): $\quad$ Almeida, Susana

Publicado por: Imprensa da Universidade de Coimbra

URL persistente:

URI:http://hdl.handle.net/10316.2/43124

DOI:

DOl:https://doi.org/10.14195/978-989-26-1300-0_23

Accessed : $\quad$ 26-Apr-2023 11:35:30

A navegação consulta e descarregamento dos títulos inseridos nas Bibliotecas Digitais UC Digitalis, UC Pombalina e UC Impactum, pressupõem a aceitação plena e sem reservas dos Termos e Condições de Uso destas Bibliotecas Digitais, disponíveis em https://digitalis.uc.pt/pt-pt/termos.

Conforme exposto nos referidos Termos e Condições de Uso, o descarregamento de títulos de acesso restrito requer uma licença válida de autorização devendo o utilizador aceder ao(s) documento(s) a partir de um endereço de IP da instituição detentora da supramencionada licença.

Ao utilizador é apenas permitido o descarregamento para uso pessoal, pelo que o emprego do(s) título(s) descarregado(s) para outro fim, designadamente comercial, carece de autorização do respetivo autor ou editor da obra.

Na medida em que todas as obras da UC Digitalis se encontram protegidas pelo Código do Direito de Autor e Direitos Conexos e demais legislação aplicável, toda a cópia, parcial ou total, deste documento, nos casos em que é legalmente admitida, deverá conter ou fazer-se acompanhar por este aviso. 


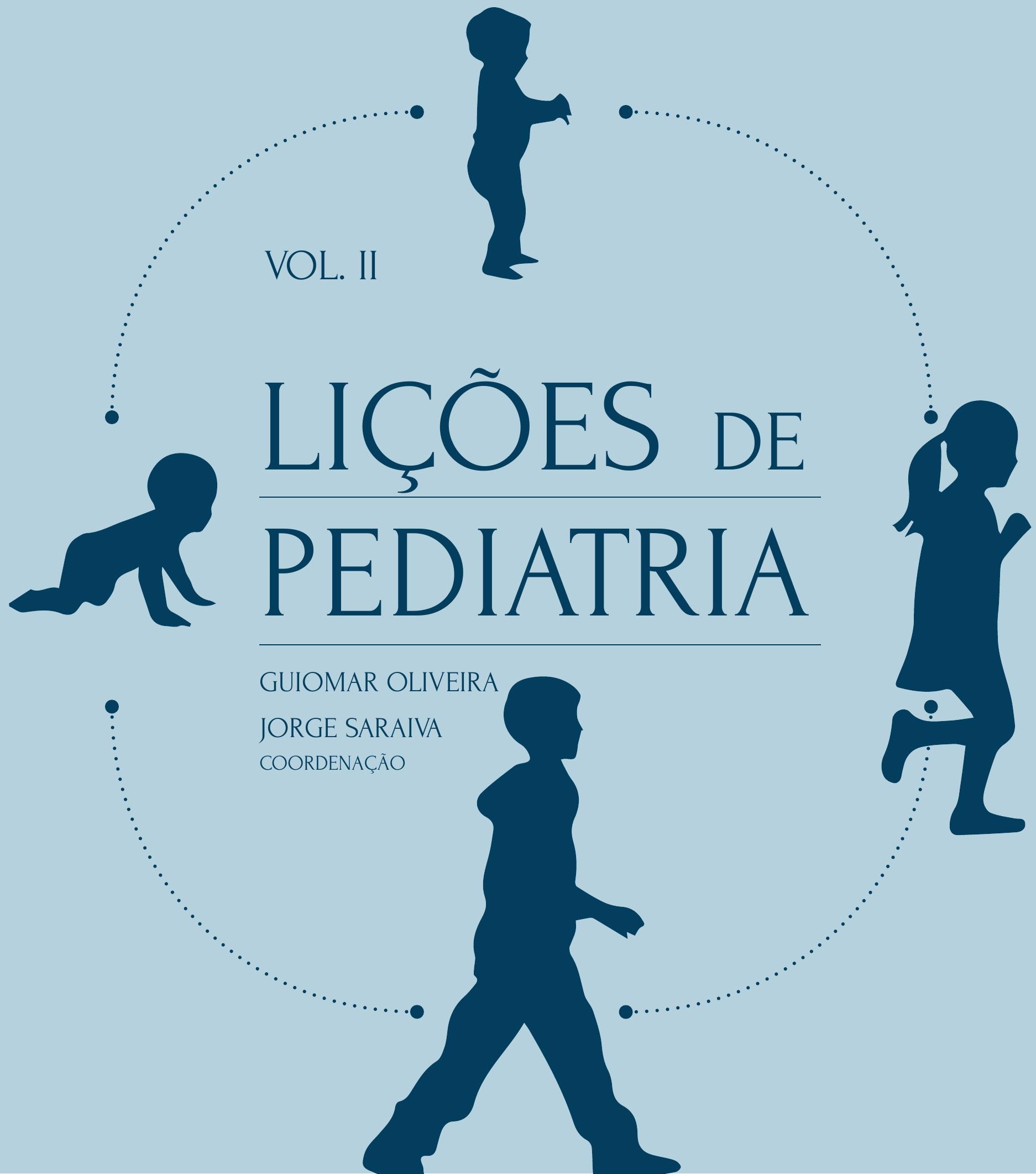


Capítulo 23.

Diarreia aguda e crónica
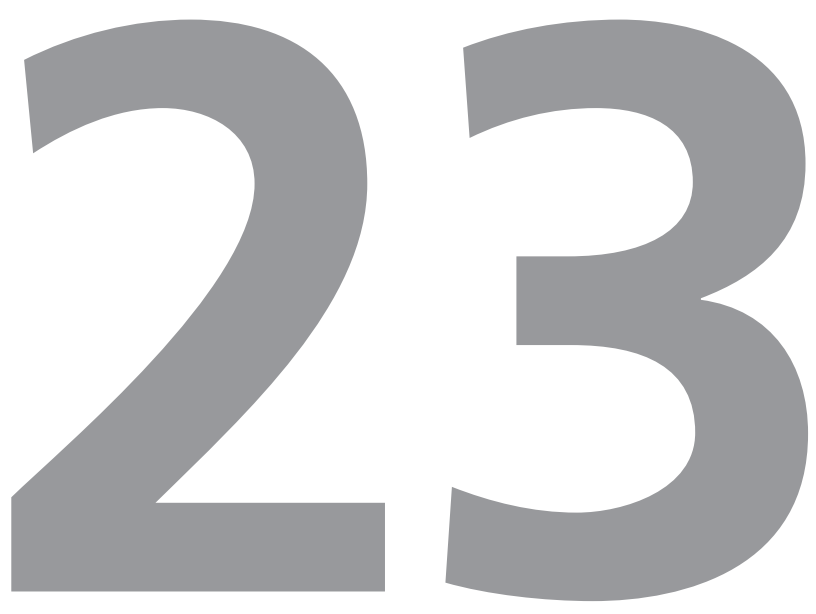

Susana Almeida 


\subsection{CONTEXTO}

Define-se diarreia como a alteração do trânsito intestinal com aumento do número e diminuição da consistência das dejeções, relativamente ao padrão habitual.

Na diarreia aguda a duração habitual é até sete dias, passando a denominar-se de diarreia crónica quando se prolonga por mais de duas semanas de evolução. Entre os sete dias e as duas semanas designa-se por diarreia prolongada.

Nas crianças é um motivo muito frequente de consulta.

\subsection{DESCRIÇÃO DO TEMA}

\subsubsection{Mecanismos fisiopatológicos}

Reconhecem-se quatro mecanismos fisiopatológicos principais: osmótico, secretor, inflamatório e por aumento da motilidade intestinal. Excecionalmente, estará envolvido apenas um destes mecanismos, sendo habitual a contribuição de vários para a explicação do caso clínico em concreto.

\section{Diarreia osmótica}

Incapacidade da mucosa intestinal absorver convenientemente substâncias osmoticamente activas (i.e. sorbitol, xilitol), por perda das enzimas envolvidas na absorção de carbohidratos (i.e. lactose) ou por sobrecarga de substâncias de elevada osmolaridade (i.e. sumos). As substâncias não absorvidas impedem a absorção normal da água endoluminal, originando diarreia, que tipicamente resolve com a pausa alimentar. Na diarreia osmótica o hiato aniónico fecal, calculado pela fórmula [290- $(\mathrm{Na}+\mathrm{K}) \times 2$ ], está aumentado (> $280 \mathrm{mOsml} / \mathrm{L})$.

\section{Diarreia secretora}

Alteração do processo de transporte enterocitário, com aumento da secreção, excedendo a capacidade de absorção. Causada geralmente por germens que aderem ou invadem as vilosidades intestinais ou que produzem enterotoxinas (i.e. cólera). A diarreia secretora é abundante e não melhora com o jejum. O hiato aniónico fecal é normal ( $<280 \mathrm{mOsml} / \mathrm{L})$.

\section{Diarreia Inflamatória}

Lesão enterocitária com diminuição da capacidade de absorção (i.e.doença inflamatória do intestino).

\section{Diarreia por aumento da motilidade}

Pode ser causada por agentes infeciosos que produzam enterotoxinas que alterem a motilidade, mas o exemplo clássico corresponde ao Síndrome do Intestino Irritável e à diarreia do hipertiroidismo.

\subsubsection{Diarreia Aguda}

A causa mais frequente de diarreia aguda é a Gastroenterite Aguda infecciosa (GEA), sendo a segunda doença aguda mais frequente, depois do catarro respiratório superior, sobretudo em crianças em idade pré-escolar. Nos países sub-desenvolvidos é ainda uma causa importante de morbilidade e mortalidade infantil.

A GEA pode ser causada por vírus, bactérias ou parasitas, é geralmente um processo 
auto limitado, exceto na infeção parasitária que frequentemente se prolonga na ausência de tratamento.

Nos países industrializados a etiologia virusal é a mais comum em todas as idades. Os agentes mais frequentes são o rotavirus, adenovirus e norovirus.

A via de transmissão das gastroenterites infecciosas é a fecal-oral. Alguns adenovirus entéricos transmitem-se também por via aérea. Os gérmens que são infeciosos com inóculos pequenos (Rotavirus, Escherichia coli, Shigella, Giardia lamblia, Amoeba) podem ser transmitidos de pessoa a pessoa.

\subsubsection{Gastroenterite aguda virusal}

O Rotavirus é o agente principal, e é mais frequente nos meses de inverno. O período de incubação é curto, de um a três dias. O pico de incidência atinge as crianças com menos de dois anos, e é mais frequente nos infantários e instituições de solidariedade social.

O início dos sintomas é súbito, com vómitos, febre e dor abdominal ligeiras e diarreia aquosa com perda de grande quantidade de líquidos, condicionando facilmente desidratação. Em cerca de um terço dos casos existe catarro superior concomitante ou prévio.

O mecanismo da diarreia é predominantemente osmótico, por lesão de células vilositárias com perda de dissacaridases. Este processo é auto limitado e completamente reversível, sendo a duração habitual do quadro de uma semana.

\subsubsection{Síndrome pós gastroenterite aguda}

É uma complicação da GEA, mais frequente entre os seis meses e os três anos. A criança apresenta um quadro típico de diarreia aguda que se prolonga para além do esperado, ou que após um período de melhoria volta a apresentar dejeções diarreicas. Está frequentemente associado a vírus que invadem e destroem o topo das vilosidades intestinais, onde se encontram a maioria das dissacaridases. Esta perda enzimática secundária origina uma diarreia osmótica por malabsorção da lactose. Com a recuperação das vilosidades e reposição das dissacaridases a criança volta a tolerar normalmente a lactose. O diagnóstico é clínico, mas em caso de dúvida pode determinar-se o pH fecal (que será ácido) e a presença de substâncias redutoras nas fezes. A redução transitória de ingestão de produtos lácteos ou a utilização de fórmulas sem lactose controlam os sintomas, até à recuperação da mucosa.

\subsubsection{Gastroenterite aguda bacteriana}

É mais frequente no verão e no outono. O período de incubação é variável e depende do agente: uma a seis horas se a causa for o Staphylococcus aureos e Bacillus cereus; um a três dias se for a Salmonella enteritidis, Escherichia coli enterotoxigénica, Shigella e Yersinia enterocolytica; uma a duas semanas no caso de ser Salmonella thyphi ou parathyphi.

As gastroenterites bacterianas associam-se geralmente a febre alta, dor abdominal importante e dependendo do mecanismo fisiopatológico da diarreia à presença de muco e/ou sangue nas fezes.

As bactérias que invadem a mucosa intestinal ou produzem citotoxinas provocam uma diarreia predominantemente inflamatória, com presença de muco e sangue (Salmonella, Shigella, Campylobacter, Yersinia, Escherichia coli enteroinvasora) 


\begin{tabular}{|c|c|c|}
\hline $\begin{array}{l}\text { Desidratação ligeira } \\
<3 \% *\end{array}$ & $\begin{array}{l}\text { Desidratação moderada } \\
3-10 \% *\end{array}$ & $\begin{array}{l}\text { Desidratação grave } \\
>10 \% *\end{array}$ \\
\hline Sem sinais desidratação & $\begin{array}{l}\text { Sede (irritabilidade/apatia) } \\
\text { Aumento FC** } \\
\text { TRC ***2- } 3 \text { segundos } \\
\text { Oligúria } \\
\text { Prega cutânea, mucosas secas } \\
\text { Olhos encovados } \\
\text { Fontanela deprimida }\end{array}$ & $\begin{array}{l}\text { Alteração estado consciência } \\
\text { Colapso cardiocirculatório } \\
\text { TRC ***>3 segundos } \\
\text { Anúria } \\
\text { Prega cutânea, mucosas secas } \\
\text { Olhos profundamente encovados } \\
\text { Fontanela deprimida } \\
\text { Ausência lágrimas }\end{array}$ \\
\hline
\end{tabular}

*\% peso corporal perdido; ** frequência cardíaca (FC); *** tempo de recoloração capilar (TRC)

Quadro 1. Sinais e sintomas que caracterizam os diferentes graus de desidratação.

As bactérias que produzem enterotoxinas, que por sua vez interferem com os mecanismos de absorção intestinal, provocam uma diarreia de predomínio secretor (Escherichia coli enterotoxigénica, Staphylococcus aureos, Vibrio cholerae, Bacillus cereus, Clostridium perfringens).

\section{Diagnóstico}

O diagnóstico de GEA é clínico. Na maioria dos casos não se justifica a pesquisa do agente etiológico.

Na história clínica devem valorizar-se os seguintes aspetos:

Anamnese detalhada, com caracterização da cronologia e características dos sintomas: início dos sintomas e duração do quadro; presença de febre; vómitos (número, quantidade aproximada); dejeções (número, volume aproximado, presença de muco ou sangue, cheiro fétido); ausência de lágrimas, sede ou irritabilidade e diminuição da diurese (sinais de desidratação).

Antecedentes relevantes: idade; portador de doença crónica (insuficiência renal, diabetes, imunodeficiência, transplantados, síndrome do intestino curto); viagens recentes a países tropicais ou endémicos para determinado agente infecioso; ingestão de alimentos suspeitos (arroz reaquecido, frango ou ovos mal cozinhados); imunização para rotavírus.

O exame objetivo permite estimar o grau de desidratação, sempre que o último peso conhecido não seja recente, para que se possa calcular a percentagem de peso perdida.

Os sinais e sintomas que caracterizam os três graus de desidratação estão descritos no quadro 1.

\section{Avaliação Analítica}

Não é necessária na maioria das crianças com GEA. 
Em crianças com desidratação moderada a severa, ou quando existe doença crónica associada, em que se prevê alterações electrolíticas ou ácido base, é recomendável realizar avaliação analítica com hemograma (hematócrito), ureia, creatinina, ionograma sérico, glicémia, e gasimetria venosa.

Na suspeita de gastroenterite de etiologia bacteriana a colheita de fezes para coprocultura pode ser útil.

A pesquisa de antigénios para vírus nas fezes por método de ELISA (rotavirus e adenovirus) não está recomendada por rotina, reservando-se para casos pontuais, em contexto de infeção nosocomial e para estudos epidemiológicos.

\section{Tratamento}

O tratamento da GEA assenta em dois pilares fundamentais, a rehidratação e a introdução precoce da alimentação. Ocasionalmente poderão estar indicados antibióticos no tratamento da gastroenterite bacteriana. A utilização precoce de probióticos parece ter uma eficácia modesta na duração da diarreia, de acordo com os estudos existentes e a utilização de fármacos anti-secretores (racecadrotil) pode estar indicada em alguns casos. A utilização de fármacos anti diarreicos está contraindicada.

\section{Princípios gerais da rehidratação:}

Sempre que possível deve preferir-se a via entérica, quer oral quer por sonda nasogástrica.O início da rehidratação deve ser precoce e deve concluir-se em cerca de quatro horas.

$\mathrm{O}$ volume de soluto de rehidratação a administrar depende do grau de desidratação: na desidratação ligeira administrar 30 a $50 \mathrm{ml} / \mathrm{Kg}$ em

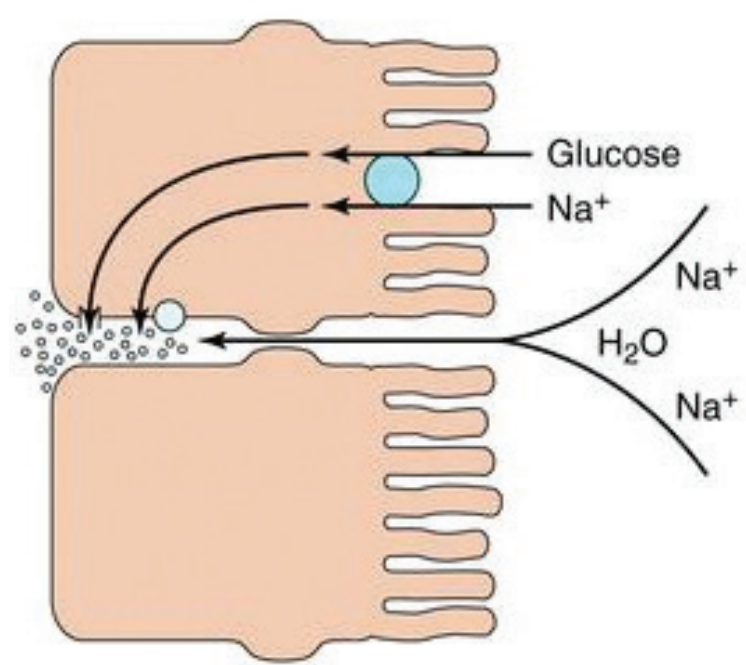

Figura 1. Transporte acoplado de sódio-glicose a nível enterocitário.

quatro a cinco horas; na desidratação moderada 75 a100 ml/Kg em três a quatro horas.

Ao volume estimado para rehidratar cada caso, deve adicionar-se o volume correspondente às perdas continuadas pelas dejeções $(10 \mathrm{ml} / \mathrm{Kg}$ por cada dejeção diarreica) e pelos vómitos (2 $\mathrm{ml} / \mathrm{Kg}$ por cada vómito).

Tipo de solutos de rehidratação oral (SRO):

A descoberta do transporte acoplado da glicose e do sódio na mucosa do intestino delgado (Figura 1), traduzindo-se em melhor absorção de sódio e água sempre que as soluções contenham glicose, permitiu a formulação dos atuais solutos de rehidratação oral. Os precursores do soluto tipo ESPGHAN (European Society of Pediatric Gastroenterology, Hepatology and Nutrition), preconizados pela Organização 


\begin{tabular}{lllllll|}
\hline Solutos & $\begin{array}{l}\mathbf{N a} \\
(\mathbf{m e q} / \mathbf{L})\end{array}$ & $\begin{array}{l}\text { Glicose } \\
(\mathbf{m m o l} / \mathbf{L})\end{array}$ & $\begin{array}{l}\mathbf{K} \\
(\mathbf{m e q} / \mathbf{L})\end{array}$ & $\begin{array}{l}\mathrm{Cl} \\
(\mathbf{m e q} / \mathbf{L})\end{array}$ & $\begin{array}{l}\text { Osmolaridade } \\
(\mathbf{m} \text { Osm/L) }\end{array}$ & $\begin{array}{l}\text { Base } \\
(\mathbf{m e q} / \mathbf{L})\end{array}$ \\
\hline OMS - 2 & 75 & 75 & 20 & 65 & 245 & 30 \\
\hline Redrate $^{\circledR}$ & 90 & 111 & 20 & 80 & 311 & 30 \\
\hline ESPGHAN & 60 & $74-111$ & 20 & $>25$ & $200-250$ & 10 \\
\hline Dioralyte $^{\circledR}$ & 60 & 90 & 20 & 60 & 240 & 10 \\
\hline Miltina E $^{\circledR}$ & 60 & 90,7 & 20 & 50 & 230 & 10 \\
\hline OralSuero $^{\circledR}$ & 60 & 80 & 20 & 38 & 212 & 14 \\
\hline Coca Cola $^{\circledR}$ & 2 & 700 & 0 & - & 750 & 13 \\
\hline Bebida Desportiva & 20 & 255 & 3 & - & 330 & 3 \\
\hline Canja & 250 & 0 & 8 & - & 500 & - \\
\hline
\end{tabular}

$\mathrm{Na}$ - sódio; K-potássio; Cl-cloro;

Quadro 2 - Composição dos diversos solutos de rehidratação oral e outros líquidos utilizados em contexto de diarreia aguda.

Mundial de Saúde (OMS), continham mais sódio, para responder às necessidades em países sub-desenvolvidos, onde a diarreia por cólera predominava, com grandes perdas daquele electrólito. Na realidade da europa os solutos hipotónicos (menos sódio) tipo ESPGHAN são perfeitamente adequados, e são os que actualmente se recomendam.

Existem vários SRO disponíveis no mercado. A sua composição e a comparação com outras bebidas utilizadas na rehidratação oral estão descritas no Quadro 2.

Na desidratação grave existe frequentemente necessidade de preenchimento vascular rápido e com grande volume de líquidos, sendo difícil a sua administração entérica, mesmo com recurso à sonda nasogástrica. Por esse motivo recorre-se habitualmente à via endovenosa.
A persistência de vómitos, comprometendo o sucesso da rehidratação via entérica, é também indicação para rehidratação por via endovenosa, nos casos de desidratações ligeiras a moderadas.

Perante uma desidratação grave com colapso cardiocirculatório, é prioritário o preenchimento vascular rápido com bólus de soro fisiológico de10 $\mathrm{ml} / \mathrm{Kg}$ a perfundir em 20 a 30 minutos, que poderá ser repetido, completando um volume de $20 \mathrm{ml} / \mathrm{Kg}$ numa hora.

Na ausência de compromisso circulatório, a rehidratação endovenosa poderá efetuar-se em 24 horas, calculando-se o ritmo de perfusão de forma a garantir a reposição do défice volume ao qual se deve acrescentar o ritmo de manutenção (necessidades hídricas basais), não esquecendo a reposição das perdas continuadas (vómitos e dejeções).

O ritmo de manutenção calcula-se com base na regra de Holliday e Segar disponivel no Quadro 3. 


\begin{tabular}{|lll|}
\hline Peso corporal & $\begin{array}{l}\text { Volume } \\
\text { total } \mathbf{2 4 h}\end{array}$ & Ritmo horário \\
\hline $\mathbf{0}$ a $\mathbf{1 0} \mathbf{K g}$ & $100 \mathrm{ml} / \mathrm{Kg}$ & $4 \mathrm{ml} / \mathrm{Kg} / \mathrm{hora}$ \\
\hline $\mathbf{1 1}$ a $\mathbf{2 0} \mathbf{K g}$ & $1000 \mathrm{ml}+$ & $40+2 \mathrm{ml} /$ \\
& $50 \mathrm{ml} / \mathrm{Kg}$ * & $\mathrm{Kg} / \mathrm{hora}$ \\
\hline $\mathbf{2 0} \mathbf{K g}$ & $1500 \mathrm{ml}+$ & $60+1 \mathrm{ml} /$ \\
& $20 \mathrm{ml} / \mathrm{Kg}^{* *}$ & $\mathrm{Kg} / \mathrm{hora}$ * \\
\hline
\end{tabular}

* por cada Kg acima dos $10 \mathrm{Kg}$;

** por cada Kg acima dos $20 \mathrm{Kg}$

Quadro 3. Necessidades hídricas basais, segundo Holliday e Segar.

O tipo de soro a utilizar depende do valor da natrémia. Perante uma desidratação hipernatrémica (natrémia > $150 \mathrm{mEq} / \mathrm{L}$ ), devem utilizar-se soros isotónicos com glicose a 5\%, e evitar descidas bruscas da natrémia (nunca superiores a 10 mEq/dia), evitando complicações cerebrais, como convulsões, hemorragia e trombose. Quanto mais elevada a natrémia, mais lenta deve ser a sua correção. $\mathrm{Na}$ desidratação hiponatrémica (natrémia < 130mEq/L) devem utilizar-se soros isotónicos para reposição da volémia e calcular o défice de sódio corporal para proceder à sua correção com $\mathrm{NaCl}$ a $3 \%$, pois valores de natrémia inferiores a $120 \mathrm{mEq} / \mathrm{L}$ predispõem, entre outras complicações, a convulsões.

\section{Reinício precoce da alimentação}

A alimentação oral deve introduzir-se precocemente, logo após a rehidratação.

Não estão recomendadas fórmulas especiais, sem lactose, hidrolizadas ou diluídas.

O aleitamento materno é recomendado sempre que possível.

Na criança mais velha, a alimentação deve obedecer às regras de uma alimentação saudável, sem restrições especiais.
Utilização de antibióticos na diarreia aguda

A antibioterapia não está indicada de forma sistemática na gastroenterite bacteriana. São indicações excecionais de antibioterapia as seguintes: infeção por Bacillus cereus e Staphilococcus aureos; baceriémia ou infeção grave a Salmonella, Shigella, Campylobacter, Vibrio cholerae e Yersinia; idade inferior a três meses; imunodeprimidos (imunodeficiências primárias e secundárias, transplantados, esplenectomizados, corticoterapia ou imunossupressão prolongada, malnutrição grave).

\section{Quando indicada, a antibioterapia deverá ser dirigida ao agente:}

Campylobacter: eriromicina ou azitromicina; Shigella: ceftriaxone; Vibrio cholerae: azitromicina ou eritromicina; Yersinia: cefotaxime ou cotrimoxazol; Salmonella typhi: ceftriaxone; Salmonella enteritidis: ampicilina, cotrimoxazol ou ceftriaxone (reduz risco de estado portador); Escherichia coli: cotrimoxazol (risco de síndrome hemolitico urémico com a estirpe 0157:H7).

\section{Prevenção da gastroenterite aguda infecciosa:}

A prevenção passa fundamentalmente por medidas universais de controlo da infeção e de segurança alimentar. Estão disponíveis no mercado duas vacinas anti-rotavirus, uma monovalente outra pentavalente.

\subsubsection{Diarreia crónica}

A diarreia crónica é o sintoma principal de uma grande variedade de doenças em idade pediátrica, algumas relativamente frequentes, outras 
raras (diarreias congénitas, tumores enterocromafins, linfangiectasia intestinal) que não serão abordadas nesta lição.

Apesar da definição mais vezes referida na literatura considerar um limite temporal superior a duas semanas de duração, alguns autores defendem um tempo de evolução que ultrapasse as quatro semanas, evitando assim investigações desnecessárias em quadros de diarreia prolongados mas auto limitados (síndrome pós-gastroenterite).

Do ponto de vista prático, a maioria das patologias que se manifesta com diarreia crónica têm impacto no estado nutricional e crescimento, e apresentam-se com outros sinais e sintomas que permitem distingui-las entre si. Essa distinção entre diarreia crónica com e sem rebate no crescimento, é fundamental na prática clínica. Patologias que geralmente não se associam a má progressão ponderal e/ou estatural: síndrome do intestino irritável; intolerância primária à lactose; hipersensibilidade às proteínas do leite de vaca não IgE mediada; erros alimentares (diarreia osmótica por abuso de sumos, sorbitol, xilitol);

\section{Patologias habitualmente associadas} a má progressão ponderal e/ou estatural: doença celíaca; doença inflamatória intestinal; giardíase; fibrose quística.

\subsubsection{Síndrome do intestino irritável}

É uma perturbação funcional do intestino, mais frequente no sexo feminino, em idade escolar e na adolescência, embora os sintomas possam ter início no segundo ano de vida. A etiopatogenia é multifactorial, resultando da interação entre fatores genéticos, ambientais, psicosociais e o eixo cérebro-intestino. Caracteriza-se por um quadro de dor abdominal recorrente, que alivia caracteristicamente com a defecação e que se associa a alteração do tipo ou frequência das dejeções. É frequente o agravamento em períodos de stresse. As queixas não são noturnas, a criança cresce bem e as dejeções podem conter muco mas a presença de sangue coloca em causa o diagnóstico. Clinicamente distinguem-se três subtipos, com predomínio de diarreia, predomínio de obstipação ou mistos. Para estabelecer este diagnóstico devem cumprir-se critérios bem estabelecidos (critérios de Roma IV) e excluir-se causas orgânicas que justifiquem o quadro (doença celíaca, doença inflamatória intestinal, intolerância à lactose). O tratamento passa pela explicação da doença à criança e aos pais e na tranquilização. A maioria dos casos melhora com medidas gerais de controlo do stresse (desporto em geral, ioga).

\subsubsection{Intolerância primária a lactose}

É uma entidade de transmissão autossómica recessiva, que condiciona a perda progressiva da atividade da lactase. A sua prevalência é variável, sendo de aproximadamente 10 a 20\% em idade adulta, nos países mediterrânicos. É uma entidade rara antes da adolescência tardia. A lactose não digerida é metabolizada pelas bactérias do cólon aumentando a produção gasosa, e os carbohidratos não digeridos atuam como substâncias osmoticamente ativas provocando diarreia. Clinicamente caracteriza-se por distensão abdominal e flatulência, diarreia aquosa e ácida. O diagnóstico pode estabelecer-se realizando uma prova de evicção de lactose, com completa resolução das queixas em dois a três dias, seguida de uma reintrodução com reprodução da clínica. O teste do hidrogénio marcado no ar expirado, 
permite fazer o diagnóstico de malabsorção deste carbohidrato após ingestão de um preparado com lactose. O tratamento consiste na evicção da lactose da dieta.

\subsubsection{Hipersensibilidade às proteínas} do leite de vaca não IgE mediada

A hipersensibilidade às proteína do leite de vaca não IgE mediada (HPLV) é uma doença imuno-mediada, com tradução clínica entre as duas semanas e os seis meses de vida, sendo mais frequente aos dois meses. Pode manifestar-se como uma retocolite (o mais frequente), uma enterocolite (envolvimento do intestino delgado) ou atingimento de todo o tubo digestivo (muito raro). A apresentação típica da retocolite é a do lactente alimentado com leite materno, com bom estado geral e boa progressão ponderal, que surge com diarreia com muco e sangue, habitualmente precedida de cólica. O quadro clínico será mais exuberante no lactente alimentado com fórmulas para lactentes, e na enterocolite haverá má progressão ponderal. Por definição, esta forma de alergia à proteína do leite de vaca não tem envolvimento sistémico nem respiratório, embora os lactentes afetados possam apresentar eczema atópico. Existem com frequência antecedentes familiares de atopia.

O diagnóstico baseia-se na clínica, apoiada por uma prova de evicção de proteínas do leite de vaca e outras que possam condicionar reacção cruzada, como a soja e os frutos secos. Para tal deve recorrer-se a uma fórmula extensamente hidrolizada, ou à evicção na dieta materna dos referidos alergenos se o aleitamento for materno exclusivo. As fórmulas parcialmente hidrolisadas ou à base de soja não são recomendadas. Constatando-se resolução da sintomatologia com a dieta, o diagnóstico de certeza exige uma prova de provocação oral cerca de quatro semanas depois. A HPLV é uma doença de bom prognóstico, em que a maioria dos lactentes tolera a proteína do leite de vaca aos 12 meses, e excecionalmente alguns persistirão com dieta de evicção até aos três anos.

\subsubsection{Doença celíaca}

A doença celíaca (DC) é uma enteropatia autoimune causada por uma intolerância total e permanente ao glúten em indivíduos com predisposição genética. A sua prevalência é de 1:100 a 1:200, sendo portanto uma doença frequente. Pode manifestar-se em qualquer idade, e a forma de apresentação é muito variável, sendo considerada uma doença multissistémica.

Nos primeiros anos de vida predominam as formas de apresentação digestiva com anorexia, diarreia crónica, distensão abdominal, desnutrição com perda acentuada das massas musculares, muito evidente a nível glúteo, e irritabilidade. As manifestações digestivas nas crianças em idade escolar e adolescentes são menos exuberantes que nos primeiros anos e podem confundir-se com a síndrome do intestino irritável. Em crianças de idade escolar, adolescentes e adultos, são mais frequentes as formas de apresentação monossintomáticas, como anemia refratária ao ferro oral, hipertransaminasémia isolada, baixa estatura isolada, atraso pubertário, amenorreia, obstipação refratária, artralgias e osteoporose, hipoplasia do esmalte dentário, aftas de repetição, fadiga crónica entre outras, pelo que é importante um elevado nível de suspeição para estabelecer o diagnóstico. Existem grupos de risco para DC, onde o diagnóstico é realizado por rastreio (familiares de primeiro 
e segundo graus de doentes celíacos, síndrome de Turner, trissomia 21, diabetes mellitus, tiroidite autoimune, algumas doenças reumatológicas entre outras). Estes indivíduos são muitas vezes assintomáticos à data do diagnóstico.

Os anticorpos actualmente disponíveis para rastreio serológico são altamente sensíveis e específicos. Perante a suspeita clínica de DC, deve proceder-se à determinação da IgA sérica total (para excluir défice de $\lg \mathrm{A}$ ) e dos anticorpos antitransglutaminase tecidular $\lg \mathrm{A}$, que estarão aumentados. Se o indivíduo apresenta valores séricos baixos de IgA devem ser doseados os anticorpos anti transglutaminase tecidular lgG. Nas crianças com menos de dois anos devem ser doseados também os anticorpos anti-gliadina desaminada do tipo IgA. Os anticorpos anti-gliadina IgG têm uma especificidade baixa para doença celiaca, podendo ser detetáveis em situações como a giardíase, por exemplo. Os anticorpos anti-endomísio IgA são doseados caso a suspeita clínica seja forte e os anteriores não forem diagnósticos. O estudo genético para a determinação da presença dos genes do complexo - major histocompatibility complex (HLA) DQ2 e DQ8 é de grande importância pois a sua negatividade tem um elevado valor preditivo negativo, ou seja, invalida praticamente a suspeita do diagnóstico de DC. Isoladamente a sua positividade não serve para o diagnóstico, pois estes haplótipos podem estar presentes em até 30\% da população saudável. O estudo genético é útil sobretudo para determinar quais dos indivíduos dos grupos de risco beneficiam do rastreio serológico regular.

$\mathrm{Na}$ presença de um rastreio serológico positivo deve proceder-se à referenciação para um centro de Gastrenterologia Pediátrica para proceder à biopsia duodeno-jejunal e confirmar o diagnóstico antes de iniciar a dieta sem glúten. Confirmando-se a presença de DC o tratamento consiste numa dieta sem glúten (presente no trigo, centeio, cevada e aveia contaminada), que normalizará os valores dos anticorpos e as alterações histológicas do intestino delgado. A dieta sem glúten deve ser cumprida para toda a vida, e sem exceções.

\subsubsection{Doença inflamatória intestinal}

A Doença inflamatória intestinal (DII) é uma entidade que engloba a doença de Crohn e a colite ulcerosa. São doenças crónicas, com início mais frequentemente na adolescência e no adulto jovem. No entanto, podem apresentar-se em qualquer idade durante a idade pediátrica, inclusivamente antes dos quatro anos de idade (doença inflamatória intestinal de inicio precoce). A fisiopatologia da DII é complexa, sabendo-se que existe predisposição genética e uma influência importante do ambiente, de infecções gastrointestinais e desequilíbrios do microbioma intestinal. A nível da mucosa intestinal, fatores relacionados com a imunidade inata e adquirida, vão desencadear uma resposta inflamatória continuada e auto perpetuada, que leva à lesão intestinal. A evolução da DIl é marcada por agudizações e períodos de remissão clínica, embora o processo inflamatório se mantenha, o que justifica as complicações a longo prazo, caso não seja convenientemente tratada (fibrose da parede intestinal, complicações fistulizantes, osteoporose e repercussão no crescimento).

\subsubsection{Doença de Crohn}

Na doença de Crohn existe um atingimento transmural do processo inflamatório crónico, 
de forma descontínua. Pode envolver qualquer segmento do tubo digestivo, desde a boca até ao ânus. A forma de apresentação depende do grau de inflamação e do segmento do tubo digestivo atingido. Na ileite terminal, a anemia e febre vespertina, associados a perda ponderal e à diminuição da velocidade de crescimento podem ser os únicos sintomas. Quando o atingimento é ileo-cólico é típica a diarreia crónica com muco e sangue, acompanhada de dor abdominal, sintomas constitucionais (astenia, anorexia, perda ponderal, febre) e rebate no crescimento. Quando presente, a doença perianal fistulizante é uma complicação da doença que tem grande impacto na qualidade de vida. As manifestações extra intestinais podem também ser o primeiro sintoma da doença, ou surgir em qualquer altura da sua evolução (artrite periférica, eritema nodoso, episclerite, úveite, litiase renal).

O diagnóstico da doença de Crohn está dependente do reconhecimento de clínica compatível, corroborada por alguns marcadores analíticos de inflamação crónica (anemia, leucocitose, trombocitose, velocidade de sedimentação globular, e proteína C reativa sérica aumentadas e calprotectina fecal aumentada) e da exclusão de infeções (Campylobacter, Yersinia, Salmonella) que possam mimetizar o quadro. A doença é confirmada pelo exame endoscópico do tubo digestivo, que deverá incluír uma endoscopia digestiva alta e uma colonoscopia com ileoscopia. O aspeto macroscópico da mucosa intestinal é muito característico, com ulcerações lineares, pseudopólipos e placas de fibrina de atingimento descontínuo. O estudo histológico da mucosa intestinal permite fazer o diagnóstico. O tratamento inicial tem como objetivo a entrada em remissão e pode passar pela corticoterapia ou alimentação oral polimérica exclusiva (preferencialmente). Todos os doentes deverão iniciar tratamento com imunossupressor (azatioprina e/ou fármacos anti inibidores dos fatores de necrose tumoral - anti TNF).

\subsubsection{Colite ulcerosa}

$\mathrm{Na}$ colite ulcerosa existe um atingimento contínuo da mucosa intestinal pelo processo inflamatório, com início no reto e extensão proximal, que frequentemente atinge todo cólon, em idade pediátrica (pancolite). A forma de apresentação mais frequente é a diarreia crónica com muco e sangue, acompanhada de dor abdominal, sintomas constitucionais e rebate no crescimento. São frequentes as queixas de diarreia noturna e tenesmo. As manifestações extra-intestinais mais frequentemente associadas à colite ulcerosa são a colangite esclerosante, pioderma gangrenoso, eritema nodoso, artrite periférica e espondilite anquilosante, uveíte e episclerite. Na colite ulcerosa de longa evolução (mais de dez anos) é importante o rastreio do carcinoma coloretal.

O diagnóstico da colite ulcerosa à semelhança da doença de Crohn, baseia-se na suspeita clínica e achados laboratoriais compatíveis com inflamação cónica, embora em casos de atingimento exclusivamente distal (proctite, proctosigmoidite) os marcadores de inflamação possam estar minimamente alterados. Deve pedir-se coprocultura para exclusão de etiologia infecciosa.

A doença é confirmada pelo exame endoscópico do tubo digestivo, que deverá incluír, em idade pediátrica, à semelhança da doença de Crohn, uma endoscopia digestiva alta e uma colonoscopia com ileoscopia. O aspecto macroscópico da mucosa intestinal é muito caracteristico, 
com edema, perda do padrão vascular e erosões/ ulcerações que atingem toda a mucosa, de forma contínua. O estudo histológico da mucosa intestinal permite confirmar o diagnóstico. O tratamento inicial tem como objetivo a entrada em remissão e pode passar pela administração de corticoterapia oral ou endovenosa dependendo da extensão e da gravidade da doença, ou pela utilização de compostos aminosalicilados 5-ASA nas formas mais distais. Nas colites extensas em idade pediátrica é aconselhável o tratamento com imunossupressor, geralmente a azatioprina em conjunto com messalasina em dose de manutenção. A utilização de anti TNF está sobretudo indicada em casos refratários à corticoterapia.

\subsubsection{Giardíase}

A Giardia lamblia é um parasita unicelular flagelado que invade o intestino delgado provocando atrofia vilositária e consequentemente malabsorção. A infeção tem um periodo de incubação de uma a duas semanas e a clínica de apresentação é muito variável, desde quadros ligeiros, semelhantes a uma gastroenterite comum, ou mesmo assintomática, até diarreia crónica com má progressão ponderal, distensão abdominal e anemia. As dejeções são fétidas, abundantes e pálidas, podendo existir esteatorreia. As formas de apresentação mais graves atingem sobretudo doentes com malnutrição prévia, com défice de IgA ou outras imunodeficiências. A giardiase é uma causa importante de diarreia do viajante. A idade de apresentação mais frequente é entre o segundo semestre de vida e os dois anos. O diagnóstico estabelece-se pela presença de quistos de Giardia nas fezes, ou muito raramente, pelo achado de trofozoitos em biópsias duodeno-jejunais.
O tratamento por via oral é eficaz, e pode realizar-se com metronidazol 15 mg/kg/dia (máximo de $750 \mathrm{mg}$ ), 3 tomas diárias, durante 5 a 7 dias; albendazol 15 mg/kg/dia (máximo de 400 mg), toma diária única, 5 dias; tinidazol 50 mg/kg (máximo de $2 \mathrm{~g}$ ), dose única.

\subsubsection{Fibrose quística}

A fibrose quística, com uma incidência na população caucasiana entre 1:3.500 e 1:5.500 recém-nascidos, é uma doença genética de transmissão autossómica recessiva, resultante de mutações do gene regulador do transportador iónico de membranas da fibrose quistíca (CFTR). Das múltiplas mutações conhecidas a mais frequente é a F508del. Trata-se de uma doença crónica, com envolvimento de vários orgãos e sistemas, com uma morbilidade e mortalidade importantes. O prognóstico tem vindo a melhorar na última década com a introdução de novas terapêuticas, como os antibióticos inalados, técnicas de cinesiterapia respiratória e a otimização nutricional.

O gene CFTR tem diversas funções, sendo o transporte de cloro e sódio através das membranas celulares o mais importante. Está distribuído por numerosos epitélios (respiratório, seios peri-nasais, glândulas sudoríparas, pâncreas, tubo digestivo, sistema reprodutivo, fígado e vias biliares e epitélio renal), com produção de secreções espessas, o que explica a sintomatologia multissistémica. No entanto, são as complicações respiratórias (infeções de repetição, bronquiectasias) e as digestivas, descritas de seguida, que mais condicionam o curso da doença em idade pediátrica.

As manifestações digestivas podem iniciar-se durante o período neonatal, com ileos meconial 
(obstrução do intestino delgado por mecónio espesso), atraso na eliminação de mecónio ou colestase neonatal principalmente por síndrome da bílis espessa. A insuficiência pancreática (secundária à autodigestão enzimática do pâncreas por obstrução canalicular) é progressiva ao longo dos primeiros anos de vida, sendo mais precoce e grave nos doentes com algumas mutações, tal como a F508del. Manifesta-se por diarreia com esteatorreia (dejeções volumosas, fétidas e briIhantes). As crianças com fibrose quística têm habitualmente apetite aumentado (exceto quando estão infetadas), já que não existe enteropatia, mas sim maldigestão dos nutrientes, com a consequente malabsorção. Nas crianças sob terapia enzimática de substituição, a obstipação, por vezes com prolapso rectal pode ser uma manifestação da doença. Outra complicação grave nos doentes com fibrose quística, principalmente nos meses quentes, é a perda excessiva de sódio e cloro pelo suor, com risco de desidratação hiponatrémica e alcalose metabólica hipoclorémica e hipocaliémica. O diagnóstico de fibrose quística pode estabelecer-se nos doentes com suspeita clinica, recorrendo ao teste do suor quantitativo que evidenciará um valor aumentado de cloro, superior a $60 \mathrm{mmol} / \mathrm{L}$ em duas determinações distintas e/ou presença de duas mutações do gene CFTR (em homozigotia ou heterozigotia composta). O diagnóstico pré-natal está disponível e recentemente a doença foi incluida no rastreio neonatal, através do doseamento da tripsina imunoreactiva, que estando aumentado, implica confirmação diagnóstica com teste do suor ou estudo genético. Actualmente, a orientação diagnóstica dos recém-nascidos detetados em rastreio realiza-se em três Centros Nacionais, um dos quais o Hospital Pediátrico de Coimbra. O tratamento dos doentes com fibrose quística é multidisciplinar, e tem como objetivo evitar as complicações pulmonares (profilaxia e tratamento precoce das infeções respiratórias) e melhorar o estado nutricional (suplementos de enzimas pancreáticas, suplementos alimentares hipercalóricos). Estão em curso diversos ensaios clínicos de fármacos com potencial para regular o gene CFTR e o poder de modificar o curso natural da doença.

\section{Leitura complementar}

Desidratação aguda na criança. M. Salgado, S. Martins et al. Saúde Infantil 2009, 31 (3)

Evidence-Based Guidelines for Management of Gastroenteritis.

A. Guarino et al. JPGN 201459 (1)

Chronic Diarrhea in Children. G Zella, E Israel. Pediatrics in Review 2012, 33 (11) 